\title{
O SANEAMENTO NA ÓtICA DE PROFISSIONAIS DE SANEAMENTO-SAÚDE-AMBIENTE: PROMOÇÃO DA SAÚDE OU PREVENÇÃO DE DOENÇAS?
}

\author{
AN APPROACH ABOUT SANITATION AMONG PROFESSIONALS OF SANITATION, \\ HEALTH AND ENVIRONMENT FIELDS: HEALTH PROMOTION OR DISEASES \\ PREVENTION?
}

\section{CEZARINA MARIa Nobre SOUZA}

Professora do Centro Federal de Educação Tecnológica do Pará. Doutoranda em Saúde Pública (ENSP/FIOCRUZ). Mestre em Tecnologia Ambiental (UnB). Graduada em Engenharia Sanitária (UFPA)

\section{CARLOS MACHADO DE FREITAS}

Professor e pesquisador da Escola Nacional de Saúde Pública da Fundação Oswaldo Cruz. Doutor em Saúde Pública (ENSP/FIOCRUZ). Mestre em Engenharia de Produção (UFRJ).Graduado em História (UFF)

Recebido: 09/04/07 Aceito: 19/12/07

\section{RESUMO}

Foram identificados entre profissionais dos setores de saneamento, saúde e ambiente, diversos discursos que tratam: 1)dos objetivos do saneamento; 2)da sustentabilidade das ações executadas; 3)da articulação intersetorial para promovê-las; 4)da participação popular nas decisôes correlatas; 5)dos objetivos da educação sanitária e ambiental no contexto do saneamento; 6) da responsabilidade pelas açôes; 7) da adaptação de tecnologias às especificidades do contexto onde são aplicadas. Buscou-se com isso verificar se a percepção que os mesmos revelam sobre tais temas se aproxima de uma visão de prevenção de doenças ou de promoção da saúde. Há predominância de discursos que apresentam uma concepção preventivista, além de discursos que não se caracterizam nem por uma visão preventivista, nem por um viés promocional.

PALAVRAS-CHAVE: Saneamento, ambiente, promoção da saúde, prevenção de doença, discursos coletivos

\begin{abstract}
Some discourses about sanitation, water supply, solid waste, urban drainage, health and environment were identified among professionals of sanitation, health and environment fields. These discourses were analyzed based on prevention diseases ideas and health promotion proposal. The results allow saying that most of them approach prevention ideas, but others are not neither preventive, nor promotional.
\end{abstract}

\section{INTRODUÇÃO}

Em Souza e Freitas (2006), seguindo uma tendência recente de reflexão crítica sobre o significado e os fundamentos da promoção da saúde, proposta por Teixeira (2001), Czeresnia e Freitas (2003) e Lefevre e Lefevre (2004), dentre outros autores, foram discutidas as bases teóricas de um saneamento voltado para a prevenção de doenças e de um saneamento focado na promoção da saúde.

Dentre outras características, para Souza e Freitas (2006), o saneamento como prevenção de doenças constitui uma intervenção de engenharia que ocorre no ambiente considerado como espaço físico, voltada para obstaculizar a transmissão de doenças e assegurar a salubridade ambiental, e que compreende a saúde como ausência de doenças.

Preocupa-se com a sustentabilidade dos sistemas e com a articulação institucional; realiza adaptaçôes tecnológicas em função das características físicas da área alvo; concentra a responsabilidade pelas açôes exclusivamente nas mãos dos engenheiros e sua equipe de educação ambiental; além do que, percebe a educação sanitária e ambiental como ferramenta para ensinar novos hábitos e costumes à população.

Por outro lado, o saneamento como promoção da saúde é uma intervenção multidimensional que se dá no ambiente, considerado em suas dimensões física, social, econômica, política e cultural. Seu objetivo é a implantação de sistemas de engenharia associada a um conjunto de ações integradas capazes de contribuir para a saúde, por sua vez definida como qualidade de vida; erradicação da doença pelo combate integral às suas causas e determinantes.

Está voltado para a sustentabilidade desses sistemas e açōes associadas e para sua adaptação ao contexto geral onde são executados; busca a articulação entre instituições e a população com vistas ao fortalecimento da mesma, compartilhando com ela e com outros setores técnicos envolvidos a respon- 
sabilidade pelas açôes; como também compreende a educação sanitária e ambiental voltada para a promoção do ser humano.

A partir de tais proposições despontou a necessidade de se investigar como os profissionais que militam na interface saneamento-saúde-ambiente apreendem os serviços de saneamento: se como ação preventivista; se como atividade promocional.

O presente trabalho tem como objetivo apresentar consideraçôes a respeito da questão supracitada, elaboradas com base em investigação realizada a partir da coleta de depoimentos de profissionais dos três setores envolvidos na relação em tela. Tais depoimentos resultaram na identificação de discursos que circulam entre esses profissionais, reveladores da sua compreensão sobre o saneamento.

Considera-se que, para os setores saneamento, saúde e ambiente, o reconhecimento desses discursos poderá contribuir para uma reflexão a respeito de como os serviços de saneamento estão sendo realizados no Brasil, seu enfoque prático e seus objetivos.

Em sua primeira seção o trabalho apresenta os procedimentos metodológicos empregados; na segunda, os resultados obtidos e as discussões correlatas; na última, a conclusão alcançada.

\section{METODOLOGIA}

Para a coleta dos depoimentos, base para a identificação e análise dos discursos, e de acordo com a aprovação do Comitê de Ética em Pesquisa da Escola Nacional de Saúde Pública Sérgio Arouca (Parecer 053/2006), foram selecionados profissionais com atuação voltada para a prática cotidiana da prestação de serviços em seu setor, pois os discursos que se desejava coletar com as entrevistas deveriam retratar essencialmente a opinião do entrevistado como resultante de sua vivência profissional diária, e não de seu cabedal de conhecimentos teóricos. A despeito de alguns profissionais serem também professores e pesquisadores, foi solicitado aos mesmos, no momento da entrevista, que respondessem às perguntas como técnicos, e não como acadêmicos.

Distante de qualquer preocupação quantitativa, ou voltada para exaurir as questões em estudo, o número de entrevistados foi fixado em 15 (cinco técnicos de cada setor) levando em conta dois aspectos: a capacidade de análise disponível, em função de fatores como recursos financeiros e tempo; os objetivos do trabalho, ligados à identificação de discursos que circulam entre profissionais. Nesse sentido, conforme será detalhado mais adiante, considerou-se que cada entrevistado revela um universo de idéias que está para além de si próprio como indivíduo; reproduz um discurso que é coletivo e que ecoa no setor. Não se tratou, portanto, de trabalhar com porta-vozes dos setores, mas, sim, de considerar que, em alguma medida, dada sua inserção profissional, cada entrevistado se constitui em portavoz de um discurso coletivo.

Por meio de informantes-chave ou a partir de conhecimento pessoal prévio dos pesquisadores, sempre utilizando o canal inter-pessoal e nunca o institucional, obedecendo ao critério de seleção supracitado, foram entrevistados apenas 13 profissionais, sendo quatro do setor saneamento, quatro do setor saúde e cinco do setor ambiente. Contando com a vantagem de, possivelmente, obter-se uma maior variedade de discursos decorrentes de diferentes realidades, foram entrevistados profissionais com atuação em duas unidades da federação situadas em regiōes geográficas diferentes: na região Sudeste, o Estado do Rio de Janeiro (nas cidades do Rio de Janeiro e Niterói) e na região Norte, o Estado do Pará (na cidade de Belém).

Pelo setor saneamento, buscou-se entrevistar engenheiros com atuação no setor público e no setor privado, diretamente ligados à prestação dos serviços de saneamento e à consultoria técnica. Foram entrevistados quatro engenheiros, designados pela letra "P" seguida de um número de chamada: P9 tem atuação em empresa pública de abastecimento de água e esgotamento sanitário; P10 atua em empresa pública responsável pelo manejo de resíduos sólidos e limpeza pública; P8 desenvolve atividades de consultoria em escritório de projetos; $\mathrm{P} 11$ atua em órgão público da administração direta, responsável pela implantação e manutenção de obras e serviços de drenagem urbana e limpeza pública. Havia a pretensão de entrevistar um quinto engenheiro com atuaçáo em empresa privada de prestação de serviços. Para tanto, foram contactados dois profissionais que, contudo, não se mostraram realmente acessíveis, não marcando efetivamente a entrevista.
Pelo setor saúde foram selecionados profissionais que atuam diretamente na prestação dos serviços de saúde à população, bem como prestam consultoria técnica. Foram entrevistados quatro profissionais: dois médicos que prestam atendimento em postos da rede pública de saúde nas áreas de pediatria (P1) e clínica geral (P7); P12 é nutricionista com atuação no setor público, especificamente em programas de atendimento integral (nutrição, saneamento, educação, etc.) a comunidades carentes; P4 é antropólogo prestador de serviços de consultoria para instituições públicas voltadas para a saúde indígena.

Foram contactados outros quatro profissionais com a intenção de obter uma quinta entrevista: dois agentes de saúde participantes do Programa Saúde da Família (PSF); um enfermeiro e um médico também pertencentes a equipes do PSF. Contudo, os primeiros não compareceram à entrevista marcada e os dois últimos alegaram absoluta falta de tempo para participar.

Pelo setor ambiente foram entrevistados quatro engenheiros: dois têm atuação em órgãos públicos de controle ambiental com experiência em fiscalização e licenciamento de projetos (P6) e planejamento de ações (P2); P13 é funcionário de instituição pública vinculada ao poder judiciário atendendo demandas ligadas mais especificamente ao tema resíduos sólidos; P5 desenvolve atividades em empresa privada de consultoria em projetos de controle ambiental. Além desses profissionais, foi entrevistado P3, um arquiteto também ligado a um órgão público de controle ambiental, com experiência em fiscalização e licenciamento de projetos.

Foi empregada a técnica da entrevista aberta com uso de um gravador, estabelecendo-se um diálogo informal com o entrevistado, tendo por base um roteiro estruturado com as seguintes perguntas: 1) Quais são os objetivos do saneamento?; 2) Como o(a) $\operatorname{Sr}(\mathrm{a})$ avalia a sustentabilidade das açōes de saneamento e seus benefícios ao longo do tempo? 3) Fala-se muito de intersetorialidade. Como o(a) $\mathrm{Sr}(\mathrm{a})$ percebe a articulação do saneamento com os outros setores? Ocorre de fato? 4) Fala-se muito em participação popular nas decisões. O que o $\mathrm{Sr}(\mathrm{a})$ pensa a respeito? 5) Qual o objetivo da educação sanitária e ambiental no contexto do saneamento, em sua opinião? 6) Qual sua visão sobre a responsabilidade pelo saneamento? É 
de toda a sociedade? É do setor? É de quem? 7) Fala-se muito sobre a adaptação das tecnologias de saneamento às peculiaridades do contexto onde estão sendo aplicadas (características físicas, hábitos, costumes e condições financeiras da população). Qual sua opiniāo sobre isso? Acontece na prática?

$\mathrm{O}$ corpus resultante das entrevistas foi submetido à técnica do Discurso do Sujeito Coletivo - DSC (Lefevre e Lefevre, 2005) para a identificação de discursos coletivos, os quais revelaram as representações sociais existentes entre os profissionais entrevistados. Estas constituem imagens que condensam um conjunto de significações; são uma maneira de interpretar e de pensar a realidade cotidiana.

A referida técnica considera que os discursos são manifestaçôes lingüísticas de um pensamento a respeito de um dado tema, podendo ser individuais ou coletivos. Constitui o caminho metodológico que torna possível, mediante a utilização de procedimentos sistemáticos, controlados, padronizados e rigorosos, partir-se do discurso individual para o discurso coletivo.

Segundo os autores citados, os variados discursos coletivos que se pretende resgatar em uma pesquisa são reconstruídos a partir de expressõeschaves (ECHs). Estas são fragmentos de discursos individuais, trechos ou transcrições literais desses discursos, reveladoras da representação social do fenômeno em estudo. Para Lefevre e Lefevre (2005), todo discurso tem uma ou mais idéias centrais (ICs). As idéias centrais são o sentido de cada discurso analisado e de cada conjunto homogêneo de ECHs, não se constituindo em interpretações, mas em descrições desse sentido.

As respostas obtidas com as 13 entrevistas realizadas foram introduzidas no programa de informática Qualiquantisoft versão $1 \mathrm{c}$, ferramenta organizadora e tabuladora dos dados que o pesquisador seleciona, facultando-lhe maior operacionalidade para a construção dos discursos.

Com o auxílio dessa ferramenta, foram resgatadas em sua literalidade as ECHs das respostas e, a partir daí, foram extraídas as ICs presentes nas mesmas. $\mathrm{Na}$ seqüência, foram agrupadas as ICs de sentido equivalente ou complementar e elaborada uma ICsíntese para cada grupo criado.

Em seguida, para cada um dos grupos de ICsíntese, foram reunidas as ECHs correspondentes, as quais foram integradas de maneira a que formassem um texto, um discurso, constituindo um único DSC para cada agrupamento.

Esses DSCs resultantes foram analisados à luz do referencial teórico adotado, já exposto em Souza e Freitas (2006), tendo em vista identificar-se como os profissionais entrevistados, militantes na interface saneamento-saúde-ambiente, apreendem os serviços de saneamento: se como ação preventivista; se como atividade promocional.

\section{RESULTADOS E DISCUSSÃO}

Foram obtidos 29 discursos coletivos no total. Tanto pela exigüidade do espaço disponível para publicação, quanto por questões estratégicas para o diálogo entre os diferentes profissionais, são apresentados e analisados a seguir apenas os 11 discursos que foram compartilhados por profissionais dos três setores em questão.

Estes revelam discursos mais orientados para uma concepção de saneamento identificada com a promoção da saúde, como também discursos ainda subjacentes a uma visão preventivista, que tem suas raízes na segunda metade do século XIX. Revelar estes discursos coletivos é um importante passo para se ampliar o diálogo entre os diferentes setores envolvidos nas açóes de saneamento e permitir que seja possível avançar na direção de um saneamento voltado não só para a prevenção de doenças, mas também, e principalmente, para a promoção da saúde.

Em relação à pergunta 1 (quais os objetivos do saneamento?), dentre os cinco DSCs resultantes, foram identificados dois discursos compartilhados por profissionais dos três setores (são designados com a letra " $n$ " os profissionais de saneamento; "s" os de saúde; "a" os de ambiente).

DSC A - O saneamento objetiva a prevenção de doenças e a qualidade de vida

P12s O saneamento básico veio para prevenir, para evitar contaminaçóes que levam ao adoecimento do ser humano. PGa É uma condição básica de sobrevivência, P7s imprescindivel para o estado geral do paciente, P9n o bem-estar da população, P1s base de praticamente tudo, pelo menos com criança. Se você não tiver um saneamento, se você não tiver a educação da mãe, ai a criança vai adoecer muito mais. P11n Tem até aqueles chavões de saneamento que 65\% das internações hospitalares são de doenças de veiculação hídrica e que para cada dólar em saneamento você economiza três dólares em internaçōes hospitalares.

P3a A gente tem um pais que não tem saneamento. P8n Hoje, a gente vê o governo brasileiro tendo uma proeminência lá fora, perante as outras naçôes, e nós temos gente morrendo das doenças mais fáceis de tratar, como diversos tipos de diarréia. Então eu vejo como objetivo principal a melhoria da qualidade de vida, a partir de açôes efetivas para a gente eliminar essas questôes.

O saneamento é apresentado no DSC A como ação que "veio para prevenir, para evitar contaminaçóes que levam ao adoecimento do ser humano". Apesar de ser mencionada a expressão "melhoria da qualidade de vida" como objetivo do saneamento, o discurso a coloca claramente como algo que se alcança como conseqüência da ausência de doenças. No trecho "então eu vejo como objetivo principal a melhoria da qualidade de vida a partir de açôes efetivas para a gente eliminar essas questôes" (doenças mais fáceis de tratar, como diversos tipos de diarréia), esse entendimento fica evidente. Portanto, neste DSC, a qualidade de vida, muitas vezes associada às idéias de promoção, aparece muito mais como resultado das açôes de prevenção do que de promoção da saúde.

DSC B - O saneamento objetiva contribuir para a saúde humana e para a preservação ambiental

P10n $O$ saneamento são as açôes voltadas para a saúde, para o bem-estar, para a qualidade de vida da população e, paralelamente, como uma decorrência necessária, para a preservação do meio ambiente. P5a São açôes de controle do ambiente para a preservação da saúde humana e dos recursos naturais. P2a $A$ importância dele é fundamental, haja vista que a gente tem visto que quase sempre as intervençôes feitas no ambiente têm reflexo no homem. P4s É para parar de morrer criancinha.

Tomando por base o conceito de ambiente discutido em Souza e Freitas (2006), no DSC B observa-se que o ambiente aparece como lugar/espaço físico onde são desenvolvidas as ações de saneamento, dentro de uma visão preventivista, e não como espaço di- 
nâmico caracterizado por dimensões física, social, econômica, política e cultural, o que se aproximaria de uma postura promocional.

Há uma referência clara à saúde como objetivo do saneamento, a qual estaria contraposta ao acometimento de diarréia por parte de crianças. Essa oposição saúde versus doença, é uma característica do enfoque preventivista, conforme discutido em Souza e Freitas (2006). Encontra-se também no DSC B uma referência à qualidade de vida. Neste caso seguindo também a mesma linha conceitual comentada no DSC A.

Dos cinco DSCs resultantes da pergunta 2 (Como o(a) sr(a) avalia a sustentabilidade das ações de saneamento e seus benefícios ao longo do tempo?), foram dois os discursos compartilhados pelos três setores.

DSC C - A preocupação com a sustentabilidade fica prejudicada pelos interesses políticos dos executores

P10n $O$ "day after" é que é o grande problema. P5a Você às vezes inaugura um aterro de residuos e, de repente, ele se transforma em lixão, porque passa para uma outra administração que não tem nenhum compromisso com aquilo ou, simplesmente, entende que é uma obra da anterior, que é bom deixar deteriorar mesmo, para mostrar que estava errado. P8n Parece que há uma ânsia muito grande em tentar denegrir tudo que o gestor passado fez e querer fazer tudo de novo. P7s Questôes políticas, questōes de uma administração desafeto da outra.

P4s Dentro da área indígena também há uma preocupação muito grande com a obra em si. Você chegar com a obra, com a caixa d'água, com o cano. Na verdade, eu acho que a sustentabilidade do saneamento em área indígena tem relação muito menos com a quantidade de pessoas que você objetivamente "salva", do que com a quantidade de pessoas que você "bota debaixo do braço"; que você controla politicamente.

O DSC C parece apresentar um saneamento que não é nem prevenção de doenças e nem promoção da saúde, pois fala de interesses que são colocados acima da saúde pública e ambiental. Trata-se de um saneamento que, se traz benefícios à população, estes são temporários e usados como "moeda" para obtenção de vantagens políticas para seus promotores.

DSC D - A preocupação com a sustentabilidade fica prejudicada pelo descuido dos gestores; pelos erros de projeto e instalação; pelo alto custo operacional e pela carência de investimentos

P12s Acho que por ser algo que despende muito dinheiro (o saneamento), eles iniciam, mas não têm aquela sustentabilidade no trabalho que realizam. P2a $A s$ obras são construidas e pouco se faz para que aquela funcionalidade se mantenha. P5a Existem também obras que são mal projetadas e mal instaladas. Elas têm um custo operacional muito alto. Então a sociedade depois não consegue manter.

P10n A manutenção do serviço em operação é a coisa mais crítica na limpeza urbana. Muito mais do que água e esgoto. Isso você só consegue com recursos humanos e financeiros. Há muito pouco investimento em capacitação. Pontuais.

O DSC D revela uma postura dos gestores do saneamento, colocada como habitual, em não dar à questão da sustentabilidade de suas ações a devida importância. Assim sendo, este também não pode ser considerado um saneamento voltado para a saúde pública e ambiental, pois tanto o saneamento preventivista, quanto o promocional, conforme afirmado em Souza e Freitas (2006), não podem prescindir da correta manutenção dos sistemas que implantam, ainda que assumindo, cada um, seus objetivos específicos: contribuir para a saúde enfrentando as causas e determinantes da doença com vistas a erradicá-la; impedir a manifestação da doença obstaculizando sua transmissão.

No que tange à pergunta 3 (Fala-se muito de intersetorialidade. Como o(a) sr(a) percebe a articulação do saneamento com os outros setores? Ocorre de fato?), foram identificados três DSCs, dos quais dois foram comuns entre os três setores.

DSC E - Não há articulação

P10n Eu percebo uma interdependência, uma inter-relação fortíssima em termos teóricos. A prática é zero. $\mathbf{P} 4 \mathbf{s}$ Não se executa na prática. P2a $O$ saneamento não é pensado de forma articulada com outras questões e políticas públicas. Se faz obras, se faz politicas de saneamento apenas com o objetivo mesmo de, às vezes, até só de sanear, sem estar articulada.

P9n Acho que minha instituição faz o seu papel. Mas, junto com a gente, no dia a dia, eu vejo as coisas separadas, a saúde atuando lá no posto de saúde. Eu acredito que ainda exista aquele programa do governo federal, Saúde da Familia, não é? Eu acredito que esteja funcionando para cá, mas a gente não vê isso. Eles não chegam à gente, ou nós não chegamos a eles... P1s porque às vezes... falta de tempo...

P13a De uma maneira geral, é difícil a articulação entre poderes. P5a Há pouco mesmo eu estava tratando aqui de órgãos públicos que não se falam. Um órgão não fala com o outro, não sabe o que o outro está fazendo, e acabam sendo conflitantes as decisóes deles. A gente tem brigas comerciais também, porque cedeu as instalaçôes, quando houve a privatização; porque um não entregava o projeto para outro, o outro não podia ler o projeto, não podia implantar os equipamentos.

O DSC E é revelador da prática de um saneamento que visa apenas à implantação de sistemas e que não se articula com os demais setores correlatos, especialmente a saúde. Por essa razão, pode-se considerar que ele aponta para um saneamento que não é nem prevenção e nem promoção, onde novamente interesses políticos, institucionais e comerciais são colocados acima do interesse da sociedade.

DSC F - Há articulação, mas muito tênue, mais em nível pessoal que institucional e deficiente na prática

P6a Eu acho que existe articulação, mas ela ainda é muito débil porque falta diálogo, falta mais passar da etapa da questão da obrigatoriedade para a questão de você ter a vontade política de realizar, das coisas funcionarem. P5a Vejo uma articulação pelo conhecimento das pessoas que trabalham. Não é institucional. P7s Na verdade, são açôes emergenciais. Após o equacionamento do problema, tudo volta ao seu estado normal.

P12s Nos municipios que a gente viaja, a gente tem visto uma integração maior na área do saneamento, até por conta da educação, de fazerem trabalhos nas escolas de coleta de lixo, por exemplo. Mas isso não é uma constante... P11n Então, no Brasil essa inter-relação é muito tênue, é muito de discurso. Tem profissionais que buscam muito fazer que essa interface seja real, não só em termos de avaliação como também de planejamento de açôes. Mas eu, sinceramente, conheço muito poucos que trabalham com a seriedade necessária, nas matrizes, para se chegar a planejar investimentos, obras, serviços. E a obra, eu não diria nem pela obra, é a obra objetivando o sistema. Pelo Brasil inteiro. Tem lagoa de estabilização que hoje é pasto de boi.

O DSC F aponta para um saneamento que busca sua articulação com 
outros setores, embora ainda com imensas dificuldades a superar, com vistas a implementar essa prática não somente na avaliação das ações, mas também em seu planejamento. Fala de um saneamento que quer se distanciar da "obra objetivando o sistema”, apenas.

Tal posicionamento parece indicar que a busca pela articulação se dá para que os sistemas continuem funcionando, ou seja, para que lagoas não mais se transformem "em pasto de boi”. Não há evidências de alguma preocupação com o empoderamento individual e coletivo da população que, conforme discutido em Souza e Freitas (2006), consiste na aquisição de poder técnico e consciência política por parte do indivíduo/comunidade para atuar em prol de sua saúde, com base no fortalecimento dos recursos humanos e materiais disponíveis.

Nesse sentido, cabe aqui lembrar que o lançamento da promoção da saúde como idéia chave do setor saúde, incluindo em seu bojo a articulação setorial e o empoderamento, veio associado a uma grande preocupação com a redução dos custos hospitalares gerados por uma população que se tornava cada vez mais cronicamente doente (Souza e Freitas, 2006). Assim, o empoderamento atuaria sobre a população como um instrumento para assegurar a redução de tais custos, não sendo, portanto, o enfoque principal da questão.

Contudo, não é consentâneo com as idéias de promoção, para além da simples modificação de hábitos, costumes e estilos de vida da população, reservar-se ao empoderamento função tão restrita e subalterna (diante das questões econômico-financeiras). $\mathrm{O}$ mesmo pode-se dizer para a articulação setorial, pois trata-se não só de uma preocupação com a otimização do funcionamento dos sistemas, mas de reconhecer a multidimensionalidade das questôes relativas ao saneamento.

A pergunta 4 (Fala-se muito em participação popular nas decisões. $\mathrm{O}$ que o $\operatorname{Sr}(\mathrm{a})$ pensa a respeito?), deu origem a sete DSCs, dos quais apenas um foi compartilhado por profissionais dos três setores em questão, o qual está exibido a seguir

DSC G - A participação popular é importante desde a fase dos projetos e depende da divulgação de informações para que exista na prática

P8n $A$ população deve interferir em todos os momentos. Eu acho que na ordem da priorização dos projetos. Desde a fase antes do projeto, porque aí você cria uma espécie de cumplicidade entre a comunidade cientifica e o povo que vive no dia-a-dia os problemas, P1s porque a população vai dizer o que é que eles estão necessitando. Agora, o governo tem que dar o que eles estão precisando e tem que educar e orientar, senão não adianta.

P13a Então, o que é importante? A informação a essa população, não é? Você prestar a informação. Não adianta você deixar ela participar e ela não ter condiçōes de se posicionar. O empreendedor tem que se chegar àquela população não apenas com um "stand" de um empreendimento, não apenas com folhetos. Ele tem que chegar e explicar, trazer a informação sobre o projeto.

O DSC G defende a ampla participação popular nos processos decisórios, com a ressalva de que o empreendedor deve fornecer à população todas as informaçôes necessárias para que ela possa se posicionar. É um discurso que não apresenta a participação popular apenas como chancela a decisões já previamente tomadas na esfera técnicoadministrativa.

Como conseqüência da pergunta 5 (Qual o objetivo da educação sanitária e ambiental no contexto do saneamento, em sua opinião?), foram identificados dois discursos.

DSC H - A educação sanitária e ambiental serve para convencer e treinar a população relativamente às obras e serviços de saneamento, e com isso reduzir custos

P1s Educação, eu achava que devia vir da escola, porque você não vai conseguir ir de casa em casa, certo? E chegar com a mãe que tem um monte de filho pra cuidar, que tem roupa pra lavar, que tem comida pra fazer e querer ensinar a ela as noçôes básicas de higiene, de saneamento. Você vai conseguir com a criança dela na escola, e a criança dela automaticamente, aos poucos, vai passando pra ela.

P3a $A$ educação ambiental deve ser constante, um trabalho de formiguinha, todo dia. P11n O objetivo é parceria, P6a é você divulgar, fazer com que as pessoas sintam-se motivadas para você fazer o saneamento, P2a para aplicar um conhecimento dentro do seu dia-a-dia. $E$ uma coisa que tem que ser internalizada nas pessoas. P9n É informar a população daquela ação, P7s sobre o uso adequado da água, o destino adequado aos dejetos $e$ tudo mais. Eu penso da incorporação de atitudes diante de uma ação. P8n
Se tivesse um trabalho permanente de educação, a gente não estaria gastando dinheiro para consertar as coisas.

No DSC H, a promoção da educação sanitária e ambiental é apresentada como uma preocupação que deve ser constante e direcionada para as novas geraçóes, tendo como objetivo informar e formar a população no que diz respeito a novos hábitos e estilos de vida e com isso reduzir custos. $\mathrm{O}$ termo "parceria", na verdade, parece ter como significado a busca da chancela da população, por meio de estratégias de convencimento, àquilo que é interessante para o projeto.

DSC I - A educação sanitária e ambiental serve para despertar na população uma consciência para a vida, inclusive sobre a relação saneamentosaúde-ambiente

P4s Eu acho que a educação sanitária e ambiental poderia servir para você saber como é que você lida com a intervenção que foi feita no seu meio ambiente e qual a origem dos seus achaques, das suas doenças, dos seus sofrimentos, P12s criando uma consciência de saúde, de ambiente, ecologia.

P5a Serve para as pessoas começarem a entender o que é uma qualidade ambiental em termos dos bens de uso, daquilo que ela está recebendo e daquilo que ela vai devolver; qual o compromisso que elas têm, da sociedade, não é? P10n Porque se as pessoas não souberem que o saneamento básico é importante para sua própria saúde, elas não vão exercer nenhuma pressão sobre os governantes para que tenham direito ao saneamento básico, que eu acho que é um direito constitucional.

P13a Serve para você trabalhar com a comunidade, dentro das escolas, para mostrar para a comunidade os prós e os contras, de levar a informação e demonstrar a necessidade da intervenção, do por que que está sendo ali, do por que que tem que ser feito.

O DSC I destaca a importância da educação sanitária e ambiental para além da adoção de novos hábitos e estilos de vida por parte da população. Parece estar falando de algo mais profundo, como o entendimento da própria vida, "uma consciência de saúde, de ambiente, ecologia", o compromisso individual e da sociedade, direitos e deveres.

A pergunta 6 (Qual sua visão sobre a responsabilidade pelo saneamento? É de toda a sociedade? É do setor? É de 
quem?), originou três DSCs. Contudo, nenhum deles foi compartilhado por profissionais dos três setores. Por essa razão, apenas são apresentadas as ICs de cada um: 1)A responsabilidade é de todos igualmente: instituições públicas, técnicos e população (P1s, P3a, P4s, P5a, P13a); 2) A responsabilidade é de todos, mas o setor técnico deve ser responsável pela indução e gestão das açôes (P2a, P6a, P8n, P11n); 3) A responsabilidade é das instituiçôes públicas do setor e de seus técnicos (P9n, P10n, P12s). Como se vê, há uma pulverização de idéias que se diferenciam fortemente em sua essência ao co-responsabilizarem a todos igualmente; ao posicionarem o setor técnico como maior responsável; ao concentrarem a responsabilidade somente no setor técnico.

A pergunta 7 (Fala-se muito sobre a adaptação das tecnologias de saneamento às peculiaridades do contexto onde estão sendo aplicadas - características físicas, hábitos, costumes e condições financeiras da população. Qual sua opinião sobre isso? Acontece na prática?), possibilitou a construção de três DSCs, dos quais dois foram compartilhados pelos três setores.

DSC J - A adaptação é necessária, já acontece, embora nem sempre, e não deve ser confundida com baixa qualidade

P1s Você não pode botar um padrão de saneamento e jogar em todas as comunidades, que elas são de niveis diferentes. P7s As adaptaçôes minimizam esse tipo de conflito. P10n Tem que se buscar soluçôes eficientes sempre adequadas até ao nosso temperamento, se eu puder ir a esse extremo, porque $\mathbf{P G}$ a não podemos trabalhar engessados.

P3a Mas, isso nem sempre acontece. P8n Estamos numa época em que a gente não precisa estar inventando o "ovo de Colombo", mas a gente ainda copia muito as coisas de fora, sem fazer a adaptação necessária. P5a Agora, o que eu vejo, e que para mim é um erro, é que você faz uma rede de esgoto numa área pobre e dimensiona os diâmetros menores. Isso não vai funcionar, porque acaba a população tendo menos nível de educação ambiental, vai jogar lixo, vai entupir. A tecnologia para pobre ou para uma classe média ou rica, ela tem que ser a mesma. O que varia são as condiçôes ambientais.

Quanto à adaptação tarifária, P11n acho que em parte os engenheiros reconhecem a necessidade, até porque tem aquele medo da inadimplência.

O DSC J se refere a um saneamen- to adaptativo, que já é uma realidade, "fora alguns deslizes", pois é objeto das preocupaçôes dos engenheiros, inclusive no que tange ao aspecto tarifário, pelo medo da inadimplência. Destaca, porém, que adaptar não pode ser sinônimo de baixa qualidade, especialmente quando se trata de obras e serviços implantados em áreas socialmente carentes.

Todos esses aspectos deixam evidente que há uma busca pela adaptação. Porém, parece que ela visa muito mais à operação dos sistemas em condições diferenciadas, de acordo com a comunidade alvo, do que atender ao papel social do saneamento. Mesmo no final, quando ressalta que a adaptação não pode implicar a queda de qualidade das obras e serviços, fica também evidenciada uma preocupação apenas com os aspectos estritos da engenharia, ligados à operação dos sistemas, para que não ocorra, no caso, a obstrução da rede.

DSC K - A adaptação não acontece na prática

P2a Eu acho que pouco se trabalha essa questão da adaptação às particularidades. P9n Em termos tarifários, essa adaptação não existe. Pelo menos na Companhia, a tarifa é igual para todo o Estado. É aquilo: chega o pacote, implanta lá e cobra.

P13a Esses critérios de adaptação aos hábitos e costumes, condiçôes físicas locais e financeiras e mesmo a capacidade técnica do município não são avaliados porque elas (as intervençôes) são escolhaspadrão. A gente vê, por exemplo, em determinado programa governamental, em que ele financiou usinas de compostagem e reciclagem. E fizeram esse padrão para todos os municípios. E o que a gente tem visto é que você chega nos municípios e tem encontrado as usinas de lixo sucateadas. Por que? Porque aquele municipio não precisava daquela usina. Para ele talvez seria melhor um aterro.

P4s Então, o que eu tenho visto acontecer não é nada adaptativo. Eu acho que tem um discurso, entendeu? Podem até as pessoas dizer: "não, nós fizemos uma reunião e eles decidiram que era uma caixa d'água que tinha que botar". Se você olhar a estrutura da tal reuniāo participativa que éfeita, você já "saca" de longe o que está acontecendo ali. A minha sensação é que as coisas vêm o tempo todo de cima para baixo.

O DSC K deixa claro que não há adaptação do saneamento às peculiaridades locais, nem mesmo em termos técnicos. Há, sim, soluções que são decididas e padronizadas "de cima para baixo", sem levar em conta aquilo que seria mais conveniente para cada local, apesar de haver um discurso em contrário. Sendo assim, este DSC se aproxima de uma postura que não sabe respeitar os critérios de ordem técnica, já discutida em Souza e Freitas (2006).

Observando-se a Tabela 1, que apresenta uma visão geral da análise dos 11 discursos obtidos, bem como os profissionais que professam cada um dos mesmos, é possível identificar alguns aspectos que merecem destaque. Por exemplo, no que tange ao tema objetivos do saneamento, pode-se verificar que, para a quase totalidade dos profissionais entrevistados, ainda que divididos entre os discursos A e B, o saneamento tem objetivos ligados à prevenção das doenças.

Quanto à sustentabilidade das ações, os discursos C e D têm o mesmo caráter não podendo ser considerados nem como preventivistas e nem como promocionais, posto que revelam que a sustentabilidade fica prejudicada por diversas questôes.

A respeito do tema articulação intersetorial, os discursos $\mathrm{E}$ e $\mathrm{F}$ assumem características diferentes: o primeiro não se enquadra nem como preventivista e nem como promocional, posto que revela a inexistência de articulação intersetorial; o segundo aproxima-se de um discurso preventivista, uma vez que admite a ocorrência de articulação, ainda que tênue e deficiente na prática. Interessante também observar que o profissional P5a professa os dois discursos, pois admite que quando há articulação ela ainda é precária.

O discurso professado pelo menor de número de profissionais, comparando-se com os demais, foi o discurso $\mathrm{G}$, relativo ao tema participação nas decisões. Isto porque esse tema foi pulverizado em sete diferentes discursos, como já dito anteriormente, sendo que somente um foi compartilhado por profissionais dos três setores, revelando-se favorável à participação.

Quanto aos objetivos da educação sanitária e ambiental, constata-se que os discursos $\mathrm{H}$ e I são opostos - um preventivista e outro promocional - havendo clara divisão da totalidade dos profissionais entre ambos, com maior compartilhamento do discurso $\mathrm{H}$.

Oposição discursiva também ocorreu sobre o tema adaptação às peculiaridades pelo saneamento, sendo que, 
nesse caso, com exceção do P12s, todos os demais se dividiram entre um discurso que admite a ocorrência da adaptação sob um enfoque preventivista, e outro que revela a inexistência da mesma, assumindo um caráter que não é nem preventivista e nem promocional.

\section{CONCLUSÃO}

A análise das entrevistas revelou que há, entre os profissionais consultados, predominância de discursos preventivistas sobre discursos promocionais. Se tal fato vier a constituir um pensamento generalizado entre todos os profissionais dos três setores, o que não pode ser avaliado com base neste trabalho, que não pretendeu ser amostral, estará revelando que a prática do saneamento no país está centrada em pressupostos limitados que, por isso mesmo, se ajustam com dificuldade ao contexto do mundo atual, marcado pela complexificação das sociedades, como afirma Carvalho (1996), pela crise da saúde pública, pela eclosão da problemática ambiental, significativamente diferente da realidade de meados do século XIX.
As entrevistas também deixaram evidente que há veiculação de muitos discursos que não se caracterizam nem por uma visão preventivista, nem por um viés promocional. Sem dúvida que tal fato é preocupante pois, também por sua vez, se vier a constituir um pensamento comum entre todos os profissionais dos três setores, estará revelando que o saneamento que se faz no Brasil se distancia de qualquer visão correlata à saúde pública e ambiental.

Esses resultados, ao revelarem convergências e oposições discursivas, ressaltam a necessidade, e mesmo a responsabilidade, de considerá-las e problematizá-las para que se possa avançar para uma concepção de saneamento identificada com a promoção da saúde. No conjunto, pode-se considerar que são nobres os objetivos do saneamento que visa contribuir para a saúde humana e a qualidade de vida por meio da prevenção de doenças e da preservação ambiental. Porém, como já discutido, mesmo estes objetivos ficam comprometidos pela não sustentabilidade das açôes por conta dos interesses políticos, do descuido dos gestores, dos erros de projeto e instalação, dos altos custos operacionais e pela carência de investimentos.

Fica evidente a ausência de mecanismos de suporte das açôes em um mundo que se torna cada vez mais interdependente e complexo. Se a articulação intersetorial se encontra cada vez mais na pauta, na prática é identificada como deficiente ou mesmo inexistente. Se a participação da população é considerada importante, no dia-a-dia é em grande parte restringida por uma concepção de educação sanitária e ambiental orientada muito mais para moldar comportamentos. Se a adaptação é considerada absolutamente necessária, no exercício diário não ocorre ou é comprometida pela não sustentabilidade dos projetos.

Ao chamar para o setor técnico grande parte da responsabilidade pelas açôes, desde sua indução até a gestão, é possível que os profissionais acabem por caminhar muito mais para centralizar em si as concepçôes e decisões acerca do saneamento, orientados por uma visão preventivista, do que para a descentralização técnica e setorial, bem como para a autonomia das populaçóes e indivíduos, ambas necessárias para a

Tabela I - Compilação analítica dos DSCs

\begin{tabular}{|c|c|c|c|}
\hline Tema & DSC e resumo da idéia central & Profissionais & Caráter do DSC \\
\hline \multirow[t]{2}{*}{$\begin{array}{l}\text { Objetivos do } \\
\text { saneamento }\end{array}$} & $\begin{array}{l}\text { A (Contribuir para prevenção de } \\
\text { doenças e qualidade de vida) }\end{array}$ & P1S, P3A, P6A, P7S, P8N, P9N, P11N, P12S & Preventivista \\
\hline & $\begin{array}{l}\text { B (Contribuir para a saúde humana } \\
\text { e para a preservação ambiental) }\end{array}$ & P2a, P4s, P5a, P10n, P12s & Preventivista \\
\hline \multirow[t]{2}{*}{$\begin{array}{l}\text { Sustentabilidade } \\
\text { das açóes }\end{array}$} & $\begin{array}{l}\text { C (Prejudicada pelos interesses } \\
\text { políticos dos executores) }\end{array}$ & P4s, P5a, P7s, P8n, P10n & $\begin{array}{l}\text { Nem preventivista } \\
\text { e nem promocional }\end{array}$ \\
\hline & $\begin{array}{l}\text { D (Prejudicada pelo descuido dos } \\
\text { gestores; erros; custo operacional; } \\
\text { falta de investimentos) }\end{array}$ & P2a, P5a, P10n, P12s & $\begin{array}{l}\text { Nem preventivista } \\
\text { e nem promocional }\end{array}$ \\
\hline \multirow[t]{2}{*}{$\begin{array}{l}\text { Articulação } \\
\text { intersetorial }\end{array}$} & E (Não há articulação) & P1s, P2a, P4s, P5a, P9n, P10n, P13a & $\begin{array}{l}\text { Nem preventivista } \\
\text { e nem promocional }\end{array}$ \\
\hline & F (Há articulação ainda deficiente) & P5a, P6a, P7s, P11n, P12s & Preventivista \\
\hline $\begin{array}{l}\text { Participação nas } \\
\text { decisões }\end{array}$ & $\begin{array}{l}\text { G (É importante e deve estar ligada } \\
\text { à divulgação de informações) }\end{array}$ & P1s, P8n, P13a & Promocional \\
\hline $\begin{array}{l}\text { Objetivos } \\
\text { da educação }\end{array}$ & $\begin{array}{c}\mathrm{H} \text { (Convencer, moldar e treinar a } \\
\text { população) }\end{array}$ & P1s, P2a, P3a, P6a, P7s, P8n, P9n, P11n & Preventivista \\
\hline $\begin{array}{l}\text { sanitária e } \\
\text { ambiental }\end{array}$ & $\begin{array}{l}\text { I (Despertar na população uma } \\
\text { consciência para a vida) }\end{array}$ & P4s, P5a, P10n, P12s, P13a & Promocional \\
\hline $\begin{array}{l}\text { Adaptação às } \\
\text { peculiaridades }\end{array}$ & $\begin{array}{l}\text { J (É necessária, já acontece e não } \\
\text { significa baixa qualidade) }\end{array}$ & P1s, P3a, P5a, P6a, P7s, P8n, P10n, P11n & Preventivista \\
\hline pelo saneamento & K (Não acontece na prática) & P2a, P4s, P9n, P13a & $\begin{array}{l}\text { Nem preventivista } \\
\text { e nem promocional }\end{array}$ \\
\hline
\end{tabular}


promoção da saúde. Nessa direção, ainda que não desejem, a complexidade do mundo social em que estão inseridos acaba por comprometer seus próprios objetivos iniciais.

Como já dito, as conclusões aqui alcançadas não podem ser extrapoladas mas, certamente, são indicadoras do quanto é necessário que a sociedade como um todo, principalmente os profissionais de saneamento, saúde e ambiente, possam refletir sobre a prática do saneamento para que ela se constitua em alavanca propulsora da qualidade de vida, do progresso e da justiça social no Brasil.

Para tanto, considerando o exposto em Souza e Freitas (2006), as ações pautadas na promoção da saúde, sem desmerecer em nada os benefícios já alcançados pela humanidade a partir de intervenções lastreadas nos pressupostos da prevenção de doenças, têm maiores chances de lograr tal objetivo, por se mostrarem mais capazes de atender às graves, complexas e crescentes demandas sociais e ambientais, na atualidade.

\section{AGRADECIMENTOS}

Ao CNPq - Conselho Nacional de Desenvolvimento Científico e Tecnológico (Brasil), pelo apoio e aos 13 entrevistados pela gentileza e acolhimento.

\section{REFERÊNCIAS}

CARVALHO, A.I. Da saúde pública às políticas saudáveis-saúde e cidadania na pós-modernidade. Ciência e Saúde Coletiva, v. 1, n.1, p.104-20, 1996.

CZERESNIA, D.; FREITAS, C.M. (orgs). Promoção da Saúde: Conceitos, Reflexôes, Tendências. Rio de Janeiro: FIOCRUZ, 176p. 2003.

LEFÈVRE, F.; LEFÈVRE, A.M.C. Promoção de saúde: a negação da negação. Rio de Janeiro: Vieira \& Lent, 166p. 2004.

LEFÈVRE, F; LEFÈVRE, A.M.C. O discurso do sujeito coletivo: um novo enfoque em pesquisa qualitativa (desdobramentos). 2 ed. Caxias do Sul: Educs, 256p. 2005.

SOUZA, C.M.N.; FREITAS, C.M. O saneamento na ótica da prevenção de doenças e da promoção da saúde. In: XXX CONGRESO DE LA ASOCIACÓN INTERAMERICANA DE INGENIERIA SANITÁRIA Y AMBIENTAL,
Punta del Leste. Anais Eletrônicos do XXX Congreso de la Asociacón Interamericana de Ingenieria Sanitária y Ambiental. AIDIS, 2006.

TEIXEIRA, C. O futuro da prevenção. Salvador, BA: Casa da Qualidade Editora, 115p. 2001.

Endereço para correspondência:

Cezarina Maria Nobre Souza Av. Nazaré, 49I/I 203 - Nazaré 66035-I 70 Belém, Pará - Brasil E-mail: cezarina.souza@oi.com.br 